\title{
대한전기학회의 편집 역사와 미래 전략
}

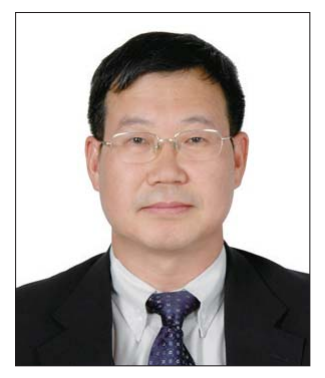

글 최재석

대한전기학회 편집위원장 경상대 전기공학과교수
1948년 창간된 『전기공학』을 필두로, 모두 4 개 부문에서 각각 국문 · 영문 논문지를 발간해오다 이들을 언어별로 합본한 국문논문지와 영문논문지를 비롯하여 총 2종의 국문논문지와 4종의 영문논문지를 발간하는 대한전기학회 의 방대한 편집 역사를 소개한다.

\section{국내 최고의 역사와 회원 수를 보유한 학회}

대한전기학회(Korea Institute of Electrical Engineers, KIEE)[web-site: http://www.kiee.or.kr) 는 지금부터 65년 전인 1947년 7월 9일 조선전기 학회(초대회장 윤일중 조선전업 사장)라는 이름으 로 창립되었으며 1949년 3월 5일에 현재의 대한전 기학회로 명명하였다. 국내 최고의 역사와 회원 수 를 가진 대한전기학회는 2012년 현재 누적 정회원 약 8천200명 누적 준회원 2천500명에 육박하는 국내 최대 학회 중 하나이다.

학회지는 창립 1년 후인 1948년 『전기공학』이라 는 이름으로 제 1 집이 창간되었다. 당시엔 논문지가 아니라 현재 발간하는 『전기의 세계』와 유사한 전 기관련 기술소개 및 소식을 전하는 학회지였다. 이
는 모든 면에서 미약했던 우리나라 전기업계를 하 나로 뭉치고 초석을 다지는 데 많은 공헌을 하였 다. 그 후 $6 \cdot 25$ 전쟁으로 잠시 발간이 중단되기도 하였으나 꾸준히 발간되어오다가 1962년 8편의 논 문이 처음으로 본 학회지에 게재되면서 논문지를 겸한 학회지로 발전하였다. 다음은 대한전기학회 의 편집 부분의 주요 연혁이다.

\section{5년간 게재한 국문 - 영문논문 약 8천 편}

2000년 학회의 크기가 급성장하여 학회 내의 각 종 연구회를 몇 개씩 묶어서 전력기술 부문회(A), 전기기기 및 에너지변환시스템기술 부문회(B), 전 기물성 - 응용기술 부문회(C) 및 정보 및 제어 부문 회(D) 등 4 개 부문회가 창립하게 되어 각 부문회별 
〈표 1〉대한전기학회 국문논문지 주요 연혁

\begin{tabular}{|c|c|}
\hline 1947. 7.9. & 조선전기학회 창립(초대회장 윤일중 조선전업 사장) \\
\hline 1948. 10. 1. & 학회지 『전기공학』제1집 창간 \\
\hline 1949. 3. 5. & 대한전기학회로 학회명칭 변경 \\
\hline 1966. 6. 30. & 전기용어집 발간 \\
\hline 1970. 2. 28. & 전기공학편람 발간 \\
\hline 1973. 12. 30. & 학회 25년사 발간 \\
\hline 1979. 1.1. & 학회지 월간 발간 \\
\hline 1982. 7.1. & 학회지를『전기학회지」와『전기학회논문지로 발간(월간) \\
\hline 1980. 4. 30. & 전기용어집 발간 \\
\hline 1997. 7. 9. & 전기학회 50년사 편찬 발간 \\
\hline 1999. 1.1. & 전기학회 논문지 $\mathrm{A}, \mathrm{B}, \mathrm{C}$ 로 발간 \\
\hline 2000. 1.1. & 전기학회논문지(각 월간) $\mathrm{A}, \mathrm{B}, \mathrm{C}-\mathrm{A}, \mathrm{B}, \mathrm{C}, \mathrm{D}$ 로 확대 분권 발행 (각 월간) \\
\hline 2001. 1. 1. & 한국학술진흥재단 등재(현재 한국연구재단으로 변경) \\
\hline 2006. 1. 1. & 전기학회논문지 통합권 발행 및 영문논문지 JEET 창간 \\
\hline 2007. 8. 1. & 국문논문지 Scopus 등재 \\
\hline 2010. 1.1. & 영문논문지(JEET) SCIE등재(2009년부터 소급적용) \\
\hline 2011.1 .1$. & 국문논문지를 전기설비부문회(E)까지 확대 포함 \\
\hline 2011. 1. 1. & 국제공동영문논문지 JICEE 발간 \\
\hline 2011. 1. 1. & DOI(Digital Object Identifier) 등재 \\
\hline 2012. 3. 1. & 국제공동영문논문지 JICEMS 발간 \\
\hline
\end{tabular}

참고: A: 전력기술 부문회, B:전기기기 및 에너지변환시스템기술 부문회, C: 전기물성·응용기술 부문회, D: 정보 및 제어 부문회, $\mathrm{E}:$ 전기 설비 부문회

로 국문논문지 및 영문논문지를 각각 발간하게 되었다. 2001년에는 국문 · 영문논문지를 모두 학술진흥재단에 등재하였으며 2004년에 각 부문회별로 영문논문지의 $\mathrm{SCI}$ 등재를 준비하게 되었다. 2006년경 각 부문회별로 발간하여오던 영문논문지에 대하여 SCI등재 신청을 하 였으나 안타깝게도 실패함에 따라 전략을 변경하여 2006년부터는 부분회별로 발간하던 영문논문지를 합 본하여 JEET (Journal of Electrical Engineering and Technology)라는 이름으로 창간하여 발간하였 다. 이때부터 국문논문지도 부문회별로 발간하던 것을 합본하여 연속으로 발간하게 되었다. 현재까지 게재된 논문 수는 총 7천908편이다. 다음의 〈그림 1) 및 〈그림 2)는 그동안 발간된 국문논문지와 영문논문지의 현황 을 연도별로 정리한 것이다. 또한 〈그림 3〉에서는 학회 의 얼굴이라 할 수 있는 학회지의 표지를 모아 보았다. 


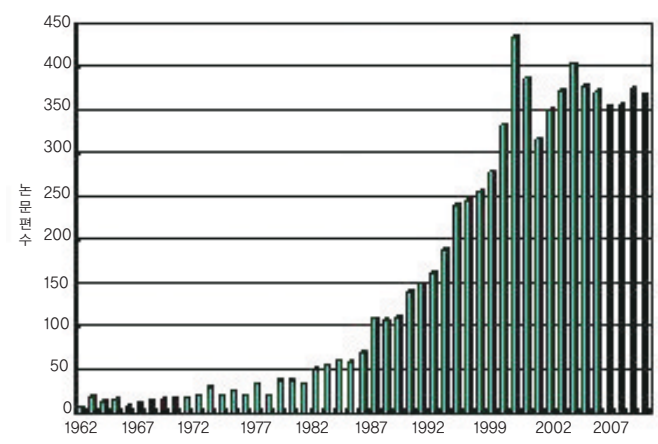

〈그림 1〉 국문논문지의 연도별 발간현황

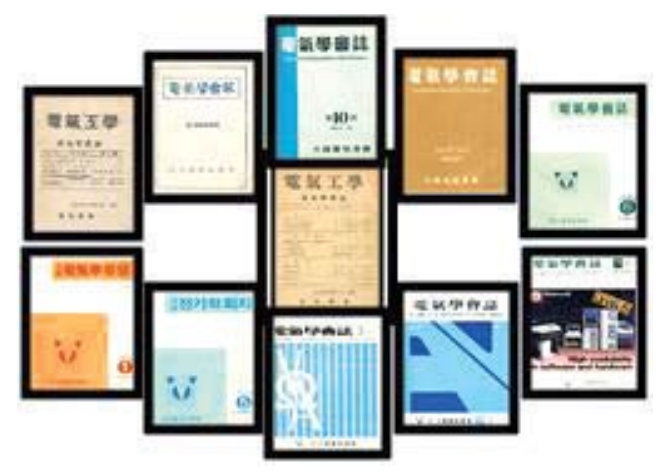

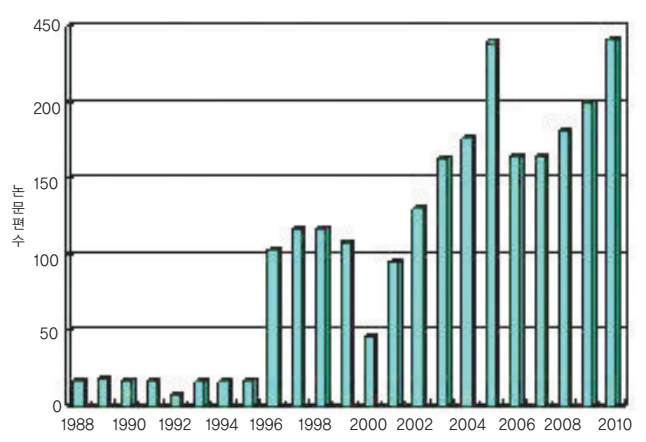

〈그림 2〉 영문논문지의 연도별 발간현황

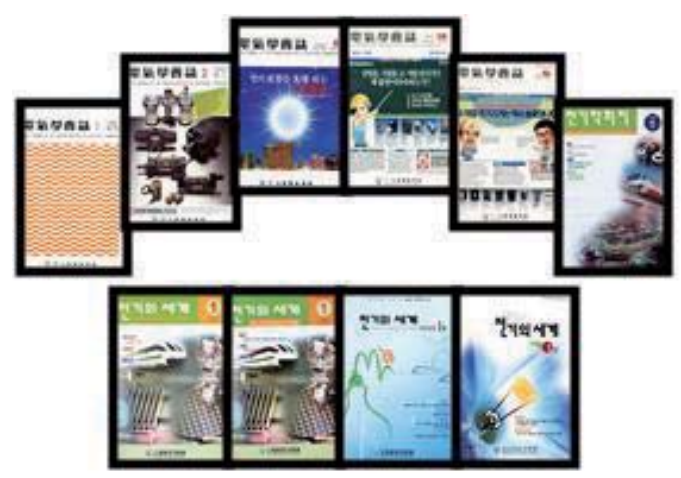

〈그림 3〉 학회지 표지의 현황

영문논문지 JEET의 SCl등재 및 선진화 전략

2010년 대한전기학회의 대표 영문논문지인 JEET가 $\mathrm{SCIE}$ 에 성공적으로 등재되었으며 특히 이때 기간이 소급되어 2009년부터 발간된 논문도 SCIE등재로 인 증받는 쾌거를 거두게 되었다. 한편, 인터넷에 힘입어 급변하는 극정보망시대에 발맞추어 2010년에는 전자 도서관을 개관했다. 총 3 만 3 천 편 14 만 쪽에 달하는 $\mathrm{DB}$ 를 완료하였으며 회원들에게는 학회지 『전기의 세
계」를 비롯하여 국문 · 영문논문지를 모두 전자메일로 무료로 발송하는 한편 학회 웹사이트를 통하여 다양한 서비스를 신속하게 제공해오고 있다. 현재 대한전기학 회에서는 『전기의 세계』라는 학회지(월간), 2 종의 국문 논문지 및 4종의 영문논문지를 발간하고 있으며 얼마 나 방대한지 그 편집위원 수만 총 200여 명에 달한다. 〈표 2〉는 대한전기학회에서 발간하는 각종 저널에 대 한 정보를 요약한 것이다.

한편 대한전기학회의 기획정책위원회에서는 2012년 보다 웅대한 꿈을 펼칠 수 있도록 영문지의 SCI등재전 
〈표 2〉 대한전기학회 발간 논문지의 등재정보 요약

\begin{tabular}{|c|c|c|c|c|c|c|}
\hline 논문지명 & $\begin{array}{l}\text { 창간 } \\
\text { 년도 }\end{array}$ & $\begin{array}{l}\text { 최근 } \\
\text { 발간 }\end{array}$ & 등재 & DOI & ISSN & 비고 \\
\hline $\begin{array}{c}\text { 국문논문지 } \\
\text { (Transactions of KIEE) }\end{array}$ & 1962 & $\begin{array}{l}\text { Vol.61 } \\
\text { No.5 }\end{array}$ & $\begin{array}{l}\text { 한국연구재단 } \\
\text { Scopus }\end{array}$ & $\begin{array}{c}\text { http://dx.doi. } \\
\text { org/10.5370/kiee.-- }\end{array}$ & 1975-8359 & 국문(월간) \\
\hline $\begin{array}{c}\text { JEET } \\
\text { (Journal of Engineering } \\
\text { and Technology) }\end{array}$ & 2006 & $\begin{array}{l}\text { Vol.7 } \\
\text { No.3 }\end{array}$ & $\begin{array}{l}\text { 한국연구재단 } \\
\text { SCIE }\end{array}$ & $\begin{array}{l}\text { http://dx.doi. } \\
\text { org/jeet.-- }\end{array}$ & $\begin{array}{l}1975-0102 \\
\text { e2093-7423 }\end{array}$ & $\begin{array}{l}\text { 영문(격월, } \\
\text { 홀수월) }\end{array}$ \\
\hline $\begin{array}{c}\text { IJCAS } \\
\text { (International Journal } \\
\text { of Control, Automation } \\
\text { \& Systems) }\end{array}$ & 2004 & $\begin{array}{l}\text { Vol.10 } \\
\text { No.3 }\end{array}$ & $\begin{array}{l}\text { 한국연구재단 } \\
\text { SCIE }\end{array}$ & $\begin{array}{l}\text { http://dx.doi. } \\
\text { org/ijcas.-- }\end{array}$ & $\begin{array}{l}1598-6446 \\
\text { e2005-4092 }\end{array}$ & $\begin{array}{c}\text { 영문(격월, } \\
\text { 짝수월)(제어로 } \\
\text { 봇시스템학회와 } \\
\text { 공동 발간) }\end{array}$ \\
\hline $\begin{array}{c}\text { JICEE } \\
\text { (Journal of Interna } \\
\text { tional Council on } \\
\text { Electrical Engineering) }\end{array}$ & 2011 & $\begin{array}{l}\text { Vol.2 } \\
\text { No.2 }\end{array}$ & & & 2233-5951 & $\begin{array}{c}\text { 영문(계간, } \\
\text { 1, 4, 7, 11)(한국, } \\
\text { 일본,중국홍콩) }\end{array}$ \\
\hline $\begin{array}{c}\text { JICEMS } \\
\text { (Journal of } \\
\text { International Conference } \\
\text { on Electrical Machines } \\
\text { and Systems) }\end{array}$ & 2012 & $\begin{array}{l}\text { Vol.1 } \\
\text { No.1 }\end{array}$ & $\begin{array}{c}\mathrm{E} 1 \\
\text { 등재신청 중 }\end{array}$ & & $\begin{array}{l}2244-6902 \\
\text { e2234-7577 }\end{array}$ & $\begin{array}{l}\text { 영문(계간, } \\
3,6,9,12) \\
\text { (한국, } \\
\text { 일본, 중국) }\end{array}$ \\
\hline
\end{tabular}

략 및 국문논문지 SCIE등재 추진을 위한 장기 - 단기 발전방향을 포함한 학회의 편집 부분의 선진화 전략을 수립하였다. 먼저, 당면한 문제와 실행안을 요약하여 소개하면 다음과 같다.

1. 심사시스템의 자동화구축: 단계별 구축 방안 마련

2. 표절방지대책시스템 도입 및 소개: CrossCheck, eTABLAST 및 Google scholar등

3. 우수논문 확보 방안 모색

4. 국문논문지의 SCIE등재 요건 확보 및 투고논문형 식 규정 정립: 2012년 상반기부터 실시

5. 각 편집위원회의 활성화 방안 마련: 2012년 하계 편집위원회 워크숍에서 논의
6. 논문 우수심사자 인증제도 및 교육프로그램

7. 편집위원의 교육체제 마련: 2012년 하반기부터 실시

8. 매년 1 회 대한전기학회 전체 편집위원회 워크숍 개최: 2012년 하계부터 시작

이 계획에는 장기적 · 단기적으로 해결해야 될 문제 들이 내포되어 있는 바, 일단 2012년에는 대한전기학 회 국문 - 영문 합동편집위원회 워크숍을 7월 하계학술 대회 중 다음의 주제로 개최하기로 하였다.

1. 국문논문지의 $\mathrm{SCIE}$ 등재 추진을 위한 준비

2. 표절방지 대책 소개 
3. 논문의 좋은 편집이란 무엇인가?

4. JEET의 SCI등재 추진전략 모색

5. 편집 부분의 예산자립화 정책 방안 수립

6. 좋은 연구

앞서 언급한 바와 같이 대한전기학회의 국문논문지 는 50 년이라는 매우 오래된 역사를 지닌다. 따라서 국 문논문지의 위치가 매우 중요하다. 개인적인 일화이지 만 필자가 몇 년 전 국문논문지 편집위원장으로 재직할 때 국문논문지의 영문제목만을 보고 원문(article)을 요청하는 편지를 유럽 등지로부터 받기도 하였다. 따라 서 현재 장기적으로 국문논문지의 SCIE등재 추진이 가능하다고 보고 보다 세밀한 전략을 수립하고 있다. 끝으로 현재 SCIE에 등재되어 있는 본 학회의 대표적 인 영문논문지인 JEET의 SCI등재를 위한 장기적 전략 을 다음과 같이 정하고 현재 논의 중에 있음을 밝힌다.

1단계(2012년) 편집시스템의 완전 자동화 구축(편집 및 심사관련 $\mathrm{D} / \mathrm{B}$ 평가 포함)

2단계(2013 2015년) $\mathrm{IF}=1.0 \sim 2.0$ 이상 추진 3단계(2016년) SCI진입 시도

\section{결언 — 질적인 향상을 도모하며}

대한전기학회는 올해로 65 년이라는 나이에 접어들 었다. 이는 본 학회가 국내외적으로 과학기술계에서 매 우 중요한 역사성과 위치를 지니고 있음을 의미한다.

나아가 본 학회는 오래된 역사에 머물지 않고 국제적 인 위상을 꾸준히 높여왔다. 더불어 여기에 머물지 않 고 최근에는 학회의 발전과 더불어 학회의 꽃인 학술과
편집에 대한 투자에도 게을리지하지 않고 보다 웅대한 비전 아래 전략을 펼치고 있다. 현재 학술지 1 종과 논 문지 6종 발간이라는 다양하고도 전문화된 논문지를 펴내는 발간 활동이 이를 말해준다. 그러나 양적인 면 보다 질적인 면에서 더욱 알찬 편집을 하기 위해서는 급변하는 편집기술의 향상, 정보서비스의 활용 방안, 저널 간의 치열한 국제적인 경쟁 및 다양한 등재주최의 등장, 특히 최근 급격하게 발달한 정보망의 세계화는 우리 편집인들에게 새로운 편집철학을 요구하고 있음 을 깊이 인식하고 이에 대한 전문가적인 수준의 편집인 을 양성할 수 있는 프로그램을 수립해가고 있다.

물론 학회의 학술지 수준은 그 학회의 구성원의 수준 을 절대로 넘을 수 없다는 사실과, 아무리 인터넷이 발 달하고 정보망이 극대화되어 펼쳐져도 역시 학술지편 집의 핵심은 그 학회의 편집을 담당한 편집위원, 심사 위원 및 사무국 담당자 등의 역량에 달려 있음을 인지 하고 있다. 아니 오히려 편집인의 역할이 더욱 중요하 다는 사실을 우리는 모두 잘 알고 있다. 따라서 본 학회 는 회원들에게 좋은 연구와 논문작성법 그리고 편집기 술을 강화하는 정책을 지속적으로 수립하고 있다. 끝으 로 지금도 본 학회의 좋은 논문을 접수하여 편집하고 심사하는 사무국 담당직원, 편집위원 및 심사위원들께 참으로 감사의 뜻을 전하고 싶다.

\section{참고문헌}

1. 대한전기학회. 『통계로 본 대한전기학회변천사』2011 년 11월(2011) 0

[출처] 과편협 뉴스레터 3호 